\title{
Assessment of the Acoustic Absorption Characteristics of Layered Composite Structures Obtained from Plates with Lignocellulosic Coatings (I)
}

\author{
ION DURBACA ${ }^{1}$, NICOLETA SPOREA ${ }^{1 *}$, OVIDIU VASILE $^{2}$ \\ ${ }^{1}$ Politehnica University of Bucharest, Faculty of Mechanical and Mechatronic Engineering, 313 Splaiul Independentei, \\ 060042, Bucharest, Romania \\ ${ }^{2}$ Politehnica University of Bucharest, Faculty of Biotechnical Systems Engineering, 313 Splaiul Independentei, 060042, \\ Bucharest, Romania
}

\begin{abstract}
The paper aims to present research on the determination of the coefficient of acoustic absorption as a function of frequency, for composite monolayer plates (made of: MDF - wooden dried agglomerated fibres with medium density, RWB - rebated wood from dried beech, PS - extruded polystyrene) and multilayer (with outer coatings of: $M D F, R W B$ and polymeric core of extruded polystyrene). The sound-absorbing behavior of such plates is highlighted in the cabins made of multilayer structures.
\end{abstract}

Keywords: composite structure, ligno-cellulosic, sound-absorption, noise level

\section{Introduction}

Acoustic pollution represents an important component of environment pollution due to its noxious and disturbing character for the entire humanity and also for other beings in the nature.

Therefore, the primary objectives of current scientific research on combating noise pollution are focused on the following strategic directions of action [1]:

- identifying potential sources of noise and of causes of noise pollution;

- development of new composite materials with high sound-absorbing properties;

- implementation of innovative technical solutions to prevent and reduce the effects of acoustic pollution (for example: sound insulation, acoustic correction, individual protection measures etc).

Revaluation of wastes by obtaining composite materials with good sound-absorption characteristics is important from a technical, economic and ecological point of view [2].

In the specialized literature there are numerous studies regarding the determination of the acoustic characteristics of composite materials, using different research and investigation methods [3 - 12].

Considering as the priority direction of research of the development of new composite materials with high sound-absorbing properties, the present paper addresses the comparative determination of the sound-absorbing capacity of two composite structures stratified with outer coatings of different ligno-cellulose nature and extruded polymeric core. For this purpose, the experimental determination of the acoustic absorption coefficient for the materials used is considered.

\section{Materials and methods}

The laminated composite plates (sandwich type) are made of materials with outer coatings of lignocellulose nature and polymeric core (Figure 1, a and b):

- wooden waste (fine woodenpowder impregnated with folmaldehidica resin - MDF), $20 \mathrm{~mm}$ thick per layer;

- rebated wood from dried beech RWB, $20 \mathrm{~mm}$ thick per layer;

- polymeric core made of extruded polystyrene (PS), $20 \mathrm{~mm}$ thick per layer;

*email: nsporea@yahoo.com. 
- transparent adhesive for pelicular gluing in thick ultra-adherent layer - Polymax / crystal express BISON.

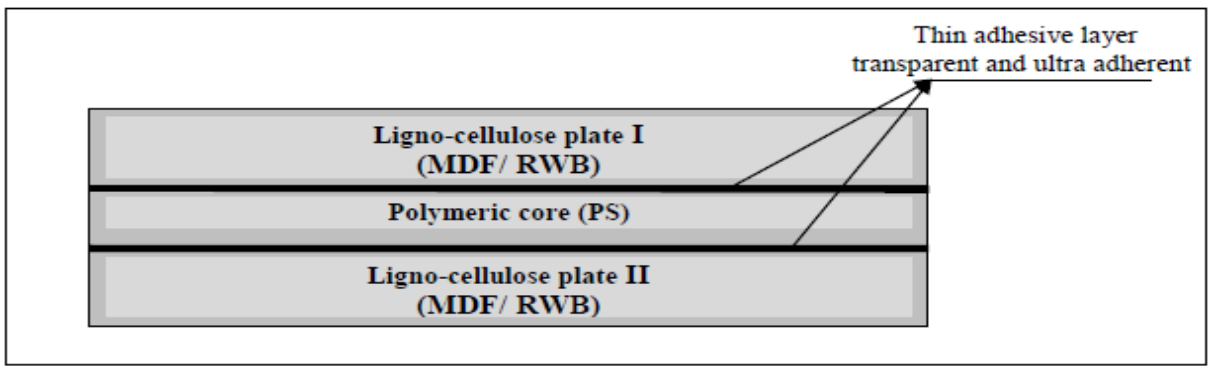

a

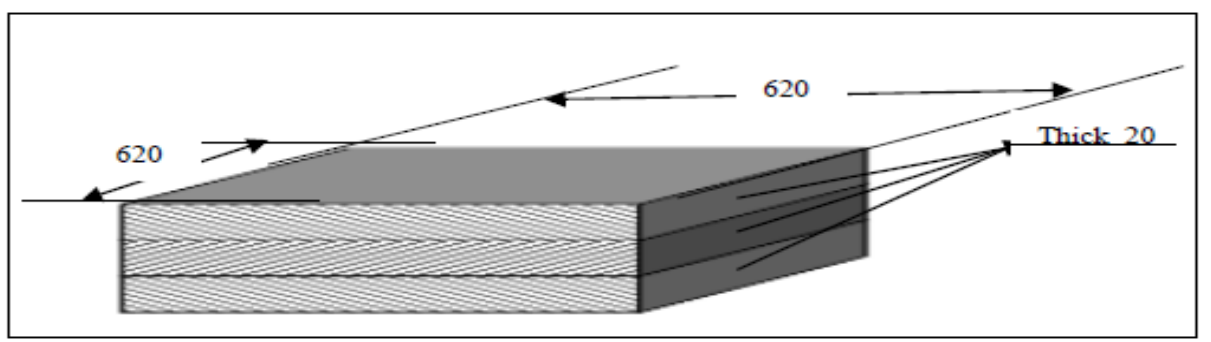

$\mathrm{b}$

Figure 1. The structure, on layers, of analysed composite plates: $\mathrm{a}$ - structure of layers; $\mathrm{b}$ - the dimensions of the composite plates.

The sound absorption coefficient $\alpha$ is used to express the capacity of the tasted material to absorb the acoustic waves of different frequency [13]. The absorption coefficient of a material varies according to frequency and the angle from where the sound or the sound wave reaches the material [14].

In order to determine the absorption coefficient, five types of circular shaped samples with a diameter of $63 \mathrm{~mm}$ were taken from the composite plates (Figure 2):

- (P1) - multilayer plates with external coatings of MDF and polymeric core of extruded polystyrene: MDF/PS/MDF;

- (P2) - multilayer plates with external coatings of RWB and polymeric core of extruded polystyrene: RWB/PS/RWB;

- $\quad(\mathrm{P} 3)$ - monolayer plates made of MDF;

- $\quad$ (P4) - monolayer plates made of RWB;

- $\quad$ (P5) - monolayer plates made of PS.

These five types of structural samples are used to determine the medium sound absorption coefficient $\alpha_{\text {med }}$, in order to make the research on acoustic absorption properties, using the sound interferometer, and the method used is in accordance with the legal standards $[15,16]$.

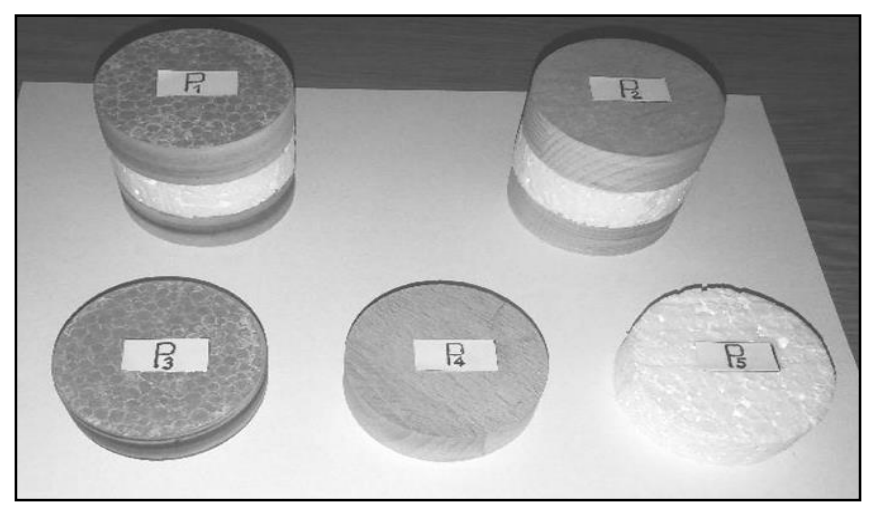

Figure 2. Types of samples of composite structures collected for the experimental study 
For characterization of sound absorption behavior of multilayered plates, there were made two experimental models (cabins/boxes) of parallelepiped shape, M1 and M2, with four lateral faces $(620 \times 620 \times 60 \mathrm{~mm})$ and a cover (500x500x60 mm) (Figure 3):

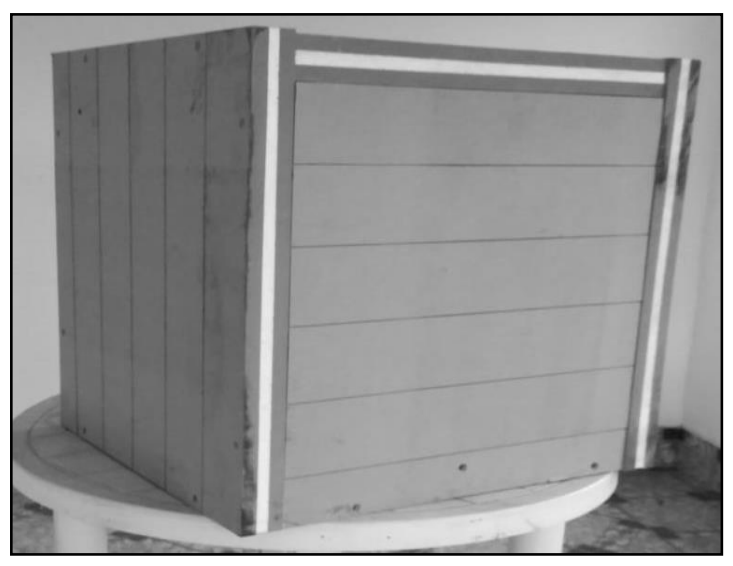

$a$.

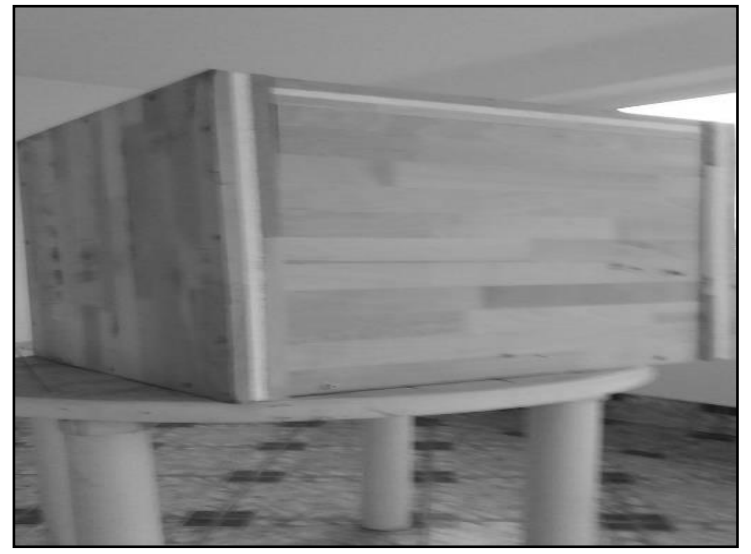

$b$.

Figure 3. The experimental model of sound absorption cabin: $a$ - model $\mathrm{M}_{1}(\mathrm{MDF} / \mathrm{PS} / \mathrm{MDF}) ; b-\operatorname{model} \mathrm{M}_{2}(\mathrm{RWB} / \mathrm{PS} / \mathrm{RWB})$.

The method of analytical calculation of the sound absorption constant for sound insulation, includes the following calculation relationships $[8,10]$ :

-the equivalent sourface with sound absorption treatment $A$, is calculated analitically with the relationship:

$$
A=\sum_{i=1}^{n} \alpha_{i} \cdot S_{i}
$$

where, $S_{i}$ is the surface with sound absortion treatment $i ; \alpha_{i}$ - is the coefficient of sound absortion of the surface $S_{i}$;

-the equivalent surface without sound absorption treatment, $A_{0}$ :

$$
A_{0}=\sum_{j=1}^{n} S_{j}
$$

where, $S_{j}$ is the surface without sound absorption treatment $j$;

-the medium coefficient of absorption of the sound insulating cabin $\alpha_{m e d}$, is characterised through relationship:

$$
\alpha_{\text {med }}=\frac{A}{A_{0}}
$$

-the sound absorption constant inside the sound insulating cabin, $R_{\alpha}$ :

$$
R_{a}=\frac{\alpha_{\text {med }}}{1-\alpha_{\text {med }}} \cdot A_{0}
$$

According to the UE directives and the national legislations, the materials are classified in classes of sound absorption (Table 1). 
Table 1. Absorption classes according to absorption coefficient [17]

\begin{tabular}{|c|c|}
\hline Absorption coefficient, $\alpha$ & Absorption acoustic class \\
\hline $1.00-0.90$ & A \\
\hline $0.85-0.80$ & B \\
\hline $0.75-0.60$ & C \\
\hline $0.55-0.30$ & D \\
\hline $0.25-0.15$ & E \\
\hline $0.10-0.00$ & No class \\
\hline
\end{tabular}

\section{Apparatus used}

The sound absorption medium coefficient $\alpha_{m e d}$ of the composite materials with sound absorption properties was determined through the method of stationary waves, in 1/3 octave, using an impedance tube (Figure 4), in the experimental installation (Figure 5), according to a standardized method [16].

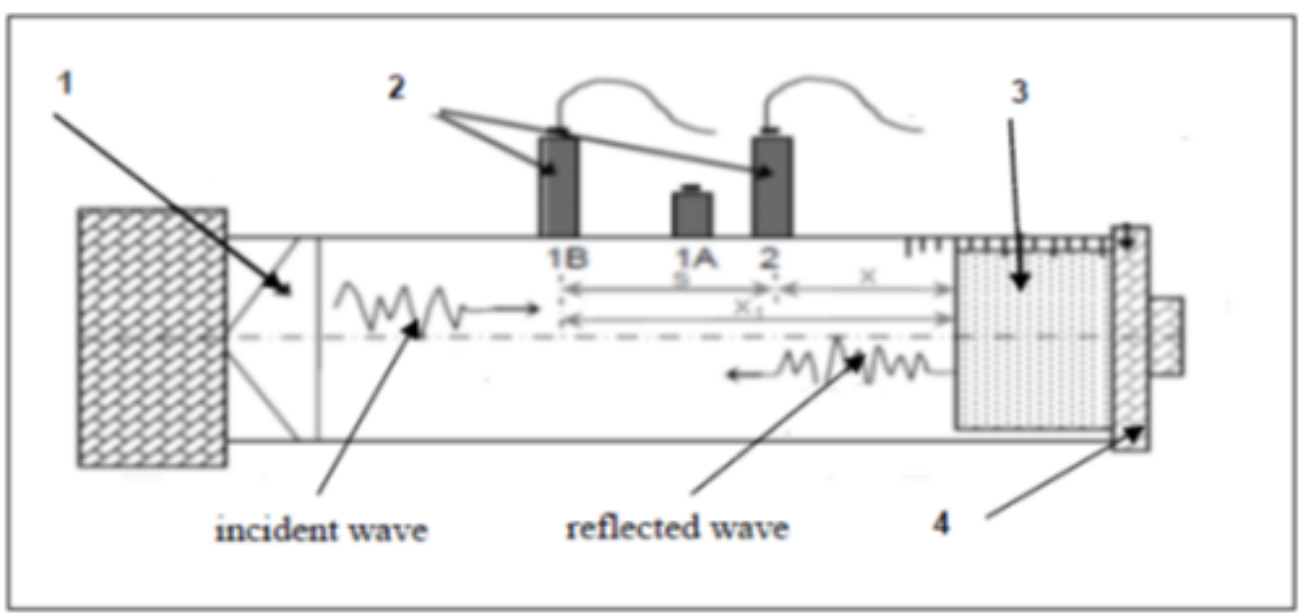

Figure 4. Scheme of impedance tube Kundt tube [16]:

1 - sound source; 2 - microphones; 3 - sound-absorbing material; 4 - mobile support.

The measurement device of the sound absorption coefficient is made of a tube which has, at one end, a movable stand on which the sample is attached, and at the other end, the acoustic source. Two identical microphones for measuring the sound pression are placed in three positions along the tube (Figure 4). The frequency range of the measured results is from 0 to $3200 \mathrm{Mhz}$. Data acquisition and process method uses hardware-software Bruël \& Kjær PULSE Platform, type 7758 [18].

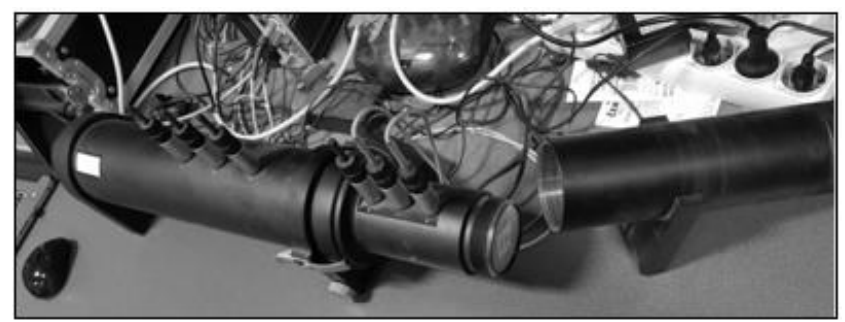

a. 


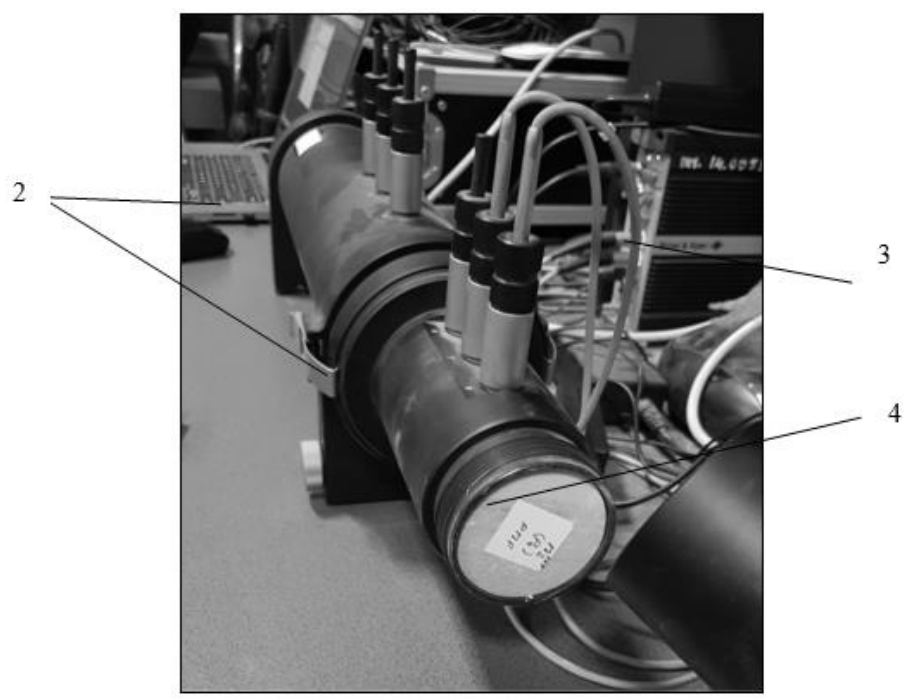

b.

Figure 5a, b. The experimental installation for samples analysis:

1 - the acoustic generator and the system of simultaneous acquisition of the signals; 2 - the tube; 3 - the signal amplifier; 4 - the sample

The equipment for signal processing contains an amplifier and a system of Fourier analysis. To determine the sound absorption constant $R$, the transfer function method is used [16]. This method is based on determining the transfer function between the two microphones, and then calculating the average acoustic absorption coefficient $\alpha_{\text {med, }}$, according to frequency.

\section{Results and discussions}

Generally, the sound absorbing capacity of a composite material depends on several parameters, including the nature of the reinforcement material and the mode of placement.

In the case of these tested materials, it is considered that it was obtained a good sound absorption capacity if the value of the medium sound absorption coefficient tends to $\alpha=1$, and the absorption percentage at this value should be mentained on a large frequency interval.

All data obtained through measurements were processed and then it was made the graphic of the dependency of the medium absorption coefficient according to frequency, for the frequency band 0 $3200 \mathrm{~Hz}$, for all five analysed samples (Figure 6).

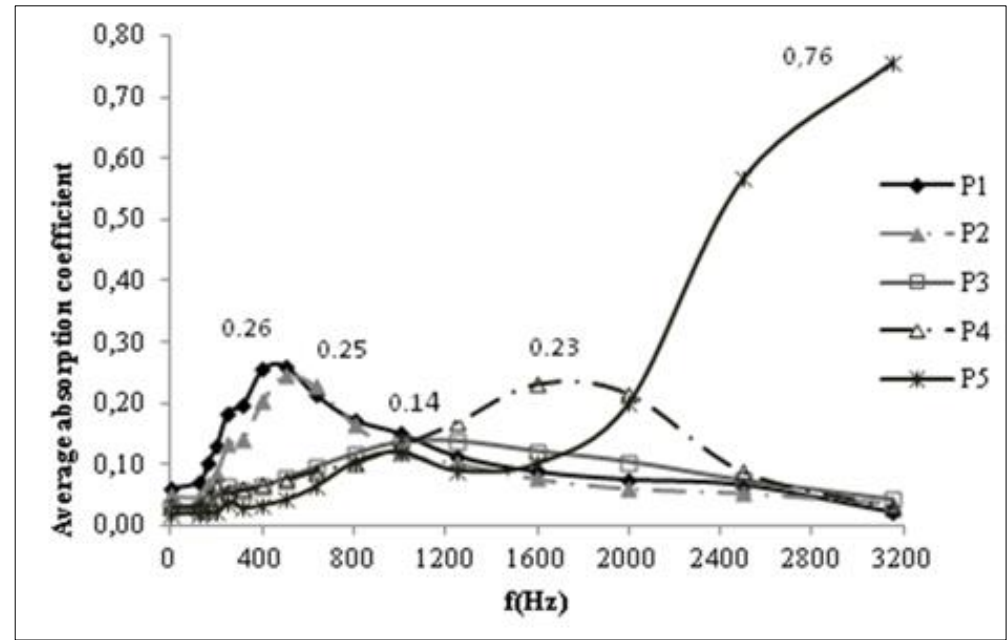

Figure 6. The variation of the medium sound absorption coefficient for the samples P1 - P5 
Analysing this diagram, we get the following results:

- at the frequency $f<200 \mathrm{~Hz}$ : coefficient $\alpha<0.1$, for all the five samples;

- at the frequency $200<f<500 \mathrm{~Hz}$ : the medium sound absorption coefficient increases, especially for samples $\mathrm{P} 1$ and $\mathrm{P} 2$, getting the maximum values of 0.26 , respectively 0.25 ;

- for the frequency band $500<f<1000 \mathrm{~Hz}$ : coefficient $\alpha$ increases for the basic materials (samples P3, P4 and P5), and decreases for samples P1 and P2;

- for frequencies $1000<f<1600 \mathrm{~Hz}$ : coefficient $\alpha$ increases only for sample $\mathrm{P} 4$ (reaching the maximum value of, $\alpha=0.23$ ), for the others it decreases;

- at the frequency $1600<f<3200 \mathrm{~Hz}$ : the medium sound absorption coefficient increases only for sample P5, for the others it decreases.

The plates with sound insulating treatment (samples P1 and P2) have got the medium coefficient of maximum absorption in the field of low frequencies and, therefore, they can be assigned to class $\mathrm{E}$ for materials with sound absorption.

Using the calculation relationships (1) - (4) is determined the analytical values of the average sound absorption coefficient and the sound absorption constant $R_{\alpha}$, for the sound insulated cabins in Figure 3. These values are presented in Table 2, compared to the acoustic characteristics values calculated for the cabins made of monolayer lingo-cellulosic composite materials, without sound insulating treatment (MDF and RWB).

Table 2. The values of the medium absorption coefficient $\alpha$ and of the sound absorption constant $R$ for $f=500 \mathrm{~Hz}, \propto_{M D F}=0.26, \propto_{R W B}=0.25, \alpha_{P S}=0,041$

\begin{tabular}{|c|c|c|c|c|}
\hline $\begin{array}{c}\text { The calculated acoustic } \\
\text { characteristic }\end{array}$ & MDF/PS/MDF & RWB/PS/RWB & RWB \\
\hline $\begin{array}{c}\text { The equivalent sound absorption } \\
\text { surface, without sound insulating } \\
\text { treatment, } A_{0}\left[\mathrm{~m}^{2}\right]\end{array}$ & 1.250 & 1.250 & 1.250 & 1.250 \\
\hline $\begin{array}{c}\text { The equivalent sound absorption } \\
\text { surface, with sound insulating } \\
\text { treatment, } A\left[\mathrm{~m}^{2}\right]\end{array}$ & 0.702 & 0.677 & 0.325 & 0.312 \\
\hline $\begin{array}{c}\text { Medium sound absorption } \\
\text { coefficient } \alpha_{\text {med }}[-]\end{array}$ & 0.561 & 0.541 & 0.26 & 0.249 \\
\hline $\begin{array}{c}\text { Sound absorption constant, } R_{\alpha} \\
{\left[\mathrm{m}^{2}\right]}\end{array}$ & 1,597 & 1.473 & 0.439 & 0.414 \\
\hline
\end{tabular}

The values obtained for the two parameters shows the fact that the most efficient composite material according to sound absorption is MDF/PS/MDF for low frequency band.

\section{Conclusions}

Layered composite materials based on ligno-cellulosic waste, with good sound absorption characteristics, may be successfully promoted, due to their low price and the minimum impact upon the environment.

The absorption coefficient of sound waves represents a very important parameter for characterisation of any type of material which is used for building or fitting out the enclosed or open spaces.

In this study it was experimentally determined the sound absorption coefficient according to frequency for monolayered composite plates (MDF, RWB and PS) and multilayered composite plates (with external coating made of MDF, RWB and polymer extruded core made of polystyrene). The values obtained through measurements for absorption coefficients at multilayered plates are not big, 
but they refer to traditional, ecological, recycled materials. Moreover, compared to basic materials, this kind of structures may be part of a class of sound absorption materials with low frequency.

The values obtained as a result of analytical calcultion for the medium sound absorption coefficient and the sound absorption constant recommend the use of multilayered plates with external coating of MDF and extruded polymer core: MDF/PS/MDF.

\section{References}

1.LAPUSAN, I.L., ARGHIR, M., Sci. and Eng., 24, 2013, p. 267.

2.BORLEA, (TIUC), A., RUSU, T., IONESCU, S., NEMES, O., Rev. Rom. Mat., 42, no.4, 2012, p. 405-414.

3.CURTU, I., STANCIU, M.D., CAMELIA COSEREANU, C., OVIDIU, V., Mater. Plast., 49(1), 2012, 68-72.

4.BRATU, M., ROPOTA, I., VASILE, O., DUMITRESCU, O., MUNTEAN, M., Rev. Rom. Mat, 41, no. 2, 2011, p. 147-154.

5.BRATU, M., DUMITRESCU, O., VASILE, O., ROPOTA, I., PASCU, L.F., Rev. Rom. Mat, 46, no. 1, 2016, p. 121-126.

6.COȘEREANU, C., LAZARESCU, C., CURTU, I., LICA, D., SOVA, D., BRENCI, L.M., STANCIU, M.D., Mater. Plast., 47(3), 2010, 341-345.

7.COȘEREANU, C., CURTU, I., LUNGUlEASA, A., LICA D., POROJAN, M., BRENCI, L., CISMARU, I., IACOB, I., Mater. Plast., 46(3), 2009, 305-309.

8.ANGHELACHE, D., The Annals of "Dunarea de Jos" University of Galati, Fascicle XIV Mechanical Engineering, 2008, p. 80-83.

9. DRAGAN, N., The Annals of "Dunarea de Jos" University of Galati, Fascicle XIV Mechanical Engineering, 2010, p. 37-44.

10. VASILE, O., GILLICH, G.R., Influence of Absorption and Insulation Properties for Phonic Treatment of Public Works Equipment, Annals of "Eftimie Murgu” University Resița, Fascicle XIX, no 1,2012 , p. 337.

11. TEODORESCU, N., STEFANESCU, M.F., PRODEA, I.M., Mater. Plast., 51, (4), 2014, 347.

12. BUSUIOCEANU, I.I., ENACHESCU, G.L., BACIU, F., DINU, G., STEFANESCU, M.F., The 7th International Conference on Structural Analysis of Advanced Materials, Bucharest, Romania, AIP Conference Proceedings 1932, No 030004, DOI: 10.1063/1.5024154.

13. ENE, GH., PAVEL, C., Introduction in vibration and noise insulation technique, Matrix Rom, Bucuresti, 2012, p. 201.

14. STANCIU, M.D., TERCIU, O.M., CURTU, I., Lignocellulosic composites - Applications in the automotive industry, Publishing house of Transilvania University of Brașov, 2014, p. 117.

15. *** SR EN ISO 10534-1, Determination of sound absorption coefficient and acoustic impedance with the inerferometer, Part 1: Stationary radio wave method, 2002.

16. *** SR EN ISO 10534-2, Determination of sound absorption coefficient and acoustic impedance with the inerferometer, Part 2: Transfer function method, 2002.

17. *** SR EN ISO 11654, Acoustics. Acoustics absorbers for use in buildings. Evaluation of acoustic absorption, 2002.

18.***Impedance Tube Kit $(100 \mathrm{~Hz}-3.2 \mathrm{kHz})$ - Type 4206-A product data, http://www.bksv. com/doc/bp1039.pdf.

Manuscript received: 5.02.2020 